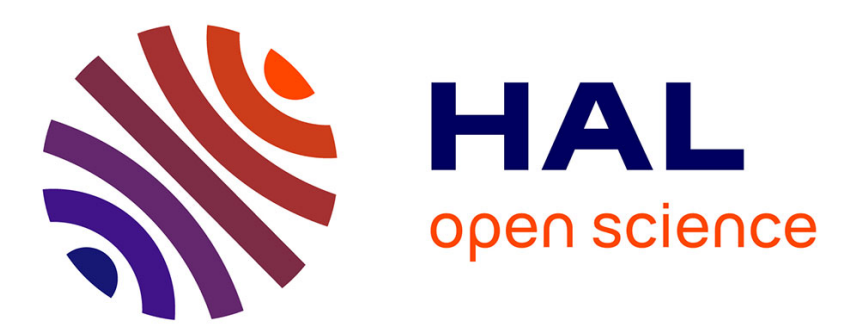

\title{
Electrochemical characterization of viscoelastic solutions of supramolecular polymers in phosphonium-based ionic liquids
}

Kahina Aoudia, Naima Brinis, Lila Chaal, Boualem Saidani, L. Benyahia, C. Chassenieux, Claude Deslouis

\section{To cite this version:}

Kahina Aoudia, Naima Brinis, Lila Chaal, Boualem Saidani, L. Benyahia, et al.. Electrochemical characterization of viscoelastic solutions of supramolecular polymers in phosphonium-based ionic liquids. Journal of electroanalytical chemistry and interfacial electrochemistry, 2015, 744, pp.101-109. 10.1016/j.jelechem.2015.02.015 . hal-01138570

\section{HAL Id: hal-01138570 \\ https://hal.science/hal-01138570}

Submitted on 2 Apr 2015

HAL is a multi-disciplinary open access archive for the deposit and dissemination of scientific research documents, whether they are published or not. The documents may come from teaching and research institutions in France or abroad, or from public or private research centers.
L'archive ouverte pluridisciplinaire HAL, est destinée au dépôt et à la diffusion de documents scientifiques de niveau recherche, publiés ou non, émanant des établissements d'enseignement et de recherche français ou étrangers, des laboratoires publics ou privés. 


\title{
Electrochemical Characterization of Viscoelastic Solutions of
}

\section{Supramolecular Polymers in phosphonium-based ionic liquids}

\author{
K. AOUDIA ${ }^{1}$, N. BRINIS ${ }^{1}$, L. CHAAL ${ }^{1}$, B. SAIDANI ${ }^{1}$, L. BENYAHIA ${ }^{2}$, \\ C. CHASSENIEUX ${ }^{2}$ et C. DESLOUIS ${ }^{3,4, *}$
}

${ }^{1}$ Laboratoire d'Electrochimie, Corrosion et de Valorisation Energétique (LECVE), Faculté de Technologie, Université A. MIRA - Bejaia (06000), Algérie

${ }^{2}$ LUNAM, Université du Maine, IMMM UMR CNRS 6283, département PCI, 1 Avenue Olivier Messiaen, 72085 Le Mans cedex 9, France

${ }^{3}$ Sorbonne Universités, UPMC Univ Paris 06, UMR 8235, Laboratoire Interfaces et Systèmes Electrochimiques (LISE), 4 place Jussieu, 75252 Paris Cedex 05, France

${ }^{4}$ CNRS, UMR 8235, LISE, Case 133, 4 place Jussieu, 75252 Paris Cedex 05, France

\section{Abstract}

We have combined electrochemical, rheological and light scattering measurements to investigate the viscoelastic character of solutions of (2,4-bis (2-ethylhexylureido) toluene) (EHUT) in toluene in the presence of two ionic liquids: (trihexyl (tetradecyl) phosphonium hexafluorophosphate "Cyphos 110") and (tris(pentafluoroethyl) trifluorophosphate "aph4cph12") used to substantially increase the solution conductivity required for the electrochemical study.

The heterogeneous rate constant $k_{0}$ of the $\mathrm{Fc} / \mathrm{Fc}^{+}$redox couple, the diffusivity $(\mathrm{DFc})$, and the equivalent capacitance values of the double layer were measured in the presence and in the absence of EHUT. For Cyphos 110, the viscosity of solutions increases in the presence of EHUT, but the diffusion current exhibited no fluctuations. By opposition, for aph4-cph12, strong fluctuations of the diffusion current allowed to assign a viscoelastic character to the solutions when EHUT is added.

Rheological and light scattering measurements revealed that the two ionic liquids act as chain stoppers for EHUT supramolecular chains. However, aph4-cph12 maintains the viscoelastic character of the EHUT solution whereas Cyphos 110 destroys the supramolecular structure. 
*Corresponding author. Tel. : +331442741 49 ; fax : +33144274074

E-mail address : claude.deslouis@upmc.fr (C. Deslouis)

Key words: Bis-urea ; toluene ; ionic liquid; EIS ; rate constant ; rheology.

\section{Introduction}

Supramolecular polymers are aggregates of small molecules which self-associate in solvent through non-covalent bonds. It was recently emphasized that they can be used in a variety of applications [1-2] and that for a given chemical structure of their monomer, their self assembled structures depend strongly on various parameters such as temperature, solvent and concentration [3]. In particular, it has been mentioned that such self assembled structures may feature a viscoelastic character at low concentration in apolar organic solvent [4-6]. Like wormlike micelles do in aqueous media [7-8], Bis-urea based low molar mass compound namely EHUT (2, 4-bis (2-ethylhexylureido) toluene) has been reported to self-assemble in nonpolar solvents into two distinct supramolecular structures, i.e. either a long hydrogenbonded filament, or thicker and more rigid tubes depending on the experimental parameters (Temperature and concentration) [6]. Moreover, hydrodynamic drag reduction (DR) in a Couette cell was observed for EHUT in octane and in toluene, allowing thereby highlighting this system as the first self-assembled drag reducer for hydrocarbon solvents [2]. As well as surfactants, which may achieve high drag reduction amounts in water [9-10], one can expect that supramolecular polymers are liable to repair themselves after mechanical degradation due to the reversible character of their self-association process. This is a decisive advantage over linear polymers which are irreversibly broken after their drag reducing action. 
The occurrence of drag reduction in both polymer and surfactant solutions has often been associated to viscoelastic properties such as the existence of a first normal stresses difference. These drag reducing solutions in turbulent flow display correlatively anomalous effects in laminar flows (e.g. Weissenberg effect, anomalous pressure drop/flow rate behavior, entrance flows) as shown for polymer solutions [11-14] and their drag reducing ability can therefore be studied in well-defined laminar flows.

It has been reported that by using electrochemical methods in polymer or surfactant aqueous solutions, the mass transfer measured towards a rotating disk electrode in laminar flow exhibits a first order transition [15-16] for a critical value of the angular velocity of the disk This transition is marked by a significant drop of the mass transfer rate which turns unsteady and is characterized by an hysteresis cycle. This behavior was caused by the elongational strain existing at the outer limit of the hydrodynamic boundary layer and was considered as a signature of the viscoelastic character of the fluid [16-18]. The transition was also accompanied by flow birefringence in the hydrodynamic boundary layer attesting the presence of elongated objects (stretched polymer chains [19] or disantangled threadlike micelles).

The main motivation for the present work was to carry out an electrochemical mass transport study with a rotating disk electrode in laminar flow for a supramolecular polymer in toluene to see if it displays the same features as those depicted previously for polymers and surfactants in aqueous solution. A particular interest of proving then the viscoelastic properties as a major indication of the drag reducing ability of such solutions is to limit direct tests in turbulent flows which imply large volumes and high flow velocities.

However, due to the weak or non polar character of such a solvent, electrochemical measurements are difficult to carry out due to low conductivity. 
To overcome this difficulty and referring to a previous work [20], we have used ionic liquids for increasing the solution conductivity. Indeed, room temperature ionic liquids have recently gained increasing interest for electrochemical applications [21-22], due to their unique chemical and physical properties, including negligible vapor pressure, high chemical and thermal stability, and also a large electrochemical potential window [23-25]. Room temperature ionic liquids when their cations and anions are properly chosen should then afford a good conductivity and can be used as supporting electrolytes in organic solvents [26]. It has been shown that room temperature ionic liquids based on two bulky ions: a phosphonium cation and a fluorophosphate anion allowed an electrochemical kinetic study with a rotating disk electrode when dissolved in toluene taking ferrocene/ferrocenium $\left(\mathrm{Fc} / \mathrm{Fc}^{+}\right)$as redox couple [20, 27-28]. Obviously such a study is quite impossible with solid ionic salts as supporting electrolytes.

In this work, we investigated the influence of a bis urea compound (EHUT) on mass transport of ferrocene in toluene to a rotating disk electrode in the presence of two ionic liquids based on a common cation, namely trihexyl(tetradecyl)phosphonium and two different anions: hexafluorophosphate (further named "Cyphos 110") and tris(pentafluoroethyl) trifluorophosphate (further named "aph4-cph12"). In parallel, the effect of the concentration of ionic liquids on the rheological and structural properties of the solutions was measured. It will be shown that the effect of the anion of the ionic liquids can be deleterious to the supramolecular structure since they act as so-called chain stoppers.

Both voltammetric response for the ferrocene oxidation and Electrochemical Impedance Spectroscopy (EIS) were analyzed. Therefore, a second objective of the work was to determine the heterogeneous rate constant $k_{0}$ of the ferrocene/ferrocenium $\left(\mathrm{Fc} / \mathrm{Fc}^{+}\right)$redox couple and the diffusivity $\left(\mathrm{D}_{\mathrm{Fc}}\right)$ in a toluene/ Cyphos 110 and in toluene/ Cyphos 110 /EHUT 
so as to complete the relevant values already obtained for those quantities in the presence of aph4-cph12 [20].

\section{Experimental section}

2.1 Materials: EHUT (2, 4-bis (2-ethylhexylureido) toluene) was synthesized by reacting racemic 2-ethylhexylamine with 2,4-toluene diisocyanate. Details of the synthesis and purification of EHUT have been reported else-where [3, 29].

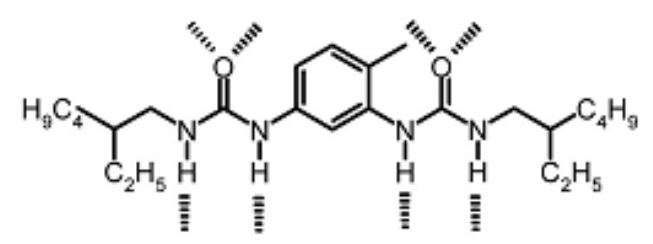

\section{Bifunctional monomer EHUT}

Toluene (>99\%) was purchased from VWR and was used as a solvent for the sample preparation without further purification. Ferrocene $(\mathrm{Fc})$ was obtained from Sigma Aldrich (98\% purity) and used at $1 \mathrm{mM}$. Cyphos 110 and cph4-cph12 were purchased from Strem Chemicals and Merck respectively. Due to the low conductivity of the solutions, the electrochemical measurements were impossible at concentrations below $0.075 \mathrm{M}$ in Cyphos 110 and could be extended down to $0.03 \mathrm{M}$ in cph4-aph12. 


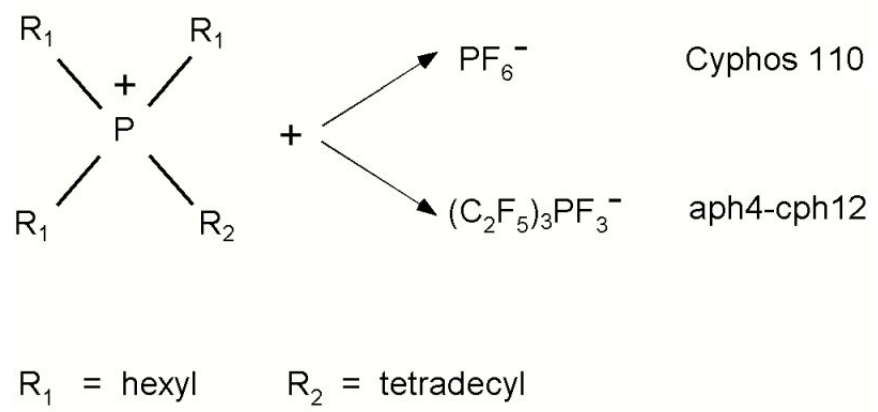

\section{$\underline{\text { Cyphos } 110 \& \text { aph4-cph12 }}$}

Samples were prepared by dissolving EHUT in toluene at $10 \mathrm{~g} / \mathrm{L}$ with $1 \mathrm{mM}$ of ferrocene by stirring over night at $50{ }^{\circ} \mathrm{C}$. The same procedure also held for EHUT/Cyphos 110 and EHUT/aph4-cph12 mixtures in order to reach stationary state. Figure 1 shows the aspect of EHUT/Cyphos 110 mixtures for two different temperatures. Above $35{ }^{\circ} \mathrm{C}$ the solutions were homogenous and transparent; below $35^{\circ} \mathrm{C}$ they displayed phase separation and turned turbid and heterogeneous. All experiments were therefore carried out at $35^{\circ} \mathrm{C}$.

\section{$<$ Figure $1>$}

\subsection{Methods:}

2.2.1 Rheology. Measurements were performed with a stress-controlled rheometer, ARG2 from TA Instruments equipped with a cone-plate geometry $\left(\right.$ angle $=1^{\circ}$, diameter $\left.=60 \mathrm{~mm}\right)$ or plate-plate $($ diameter $=40 \mathrm{~mm})$ depending on the viscosity of the sample. The temperature was controlled with a Peltier system. The samples were protected by a solvent trap to prevent evaporation.

Steady-state shear stress was measured as function of the applied shear rate ranging from $10^{-2}$ to $10^{3} \mathrm{~s}^{-1}$. 


\subsubsection{Light Scattering.}

Light scattering measurements were done using an ALV-CGS3 system operating with a vertically polarized laser (wavelength $\lambda=632 \mathrm{~nm}$ ) at various scattering angles $\theta$ between 70 and $150^{\circ}$, corresponding to scattering vectors $\mathrm{q}=4 \pi \mathrm{n} / \lambda \sin (\theta / 2)$ ranging from 0,017 to 0,029 $1 / \mathrm{nm}$ with $\mathrm{n}$ the refractive index of the solvent. The duration of the experiments was set to 6 minutes per angle in order achieving a good signal-to-noise ratio for correlation functions.

The solvent was filtered through $0.2 \mu \mathrm{m}$ Teflon filter before preparing solutions. The intensity autocorrelation functions $\mathrm{g}_{2}(\mathrm{t})$ obtained from dynamic light scattering were analyzed in terms of a continuous distribution of relaxation times (eq. 1):

$g_{1}(t)=\int_{0}^{\infty} A(\tau) \exp (-t / \tau) d \tau$

Here $\mathrm{g}_{1}(\mathrm{t})$ is the normalized electric field autocorrelation function and is related to $\mathrm{g}_{2}(\mathrm{t})$ via the so-called Siegert relation. The REPES routine was used to obtain the distribution of relaxation time $\mathrm{A}(\tau)[30]$.

The hydrodynamic correlation length, $\xi$, was calculated by using the Stokes-Einstein relation (eq. 2):

$\xi=\frac{k T}{6 \pi \eta\left(1 / \tau q^{2}\right)}$

where $\mathrm{k}$ is the Boltzman's constant, $\mathrm{T}$ the temperature and $\eta$ the viscosity of the solvent. 


\subsubsection{Electrochemistry.}

Electrochemical measurements have been performed in toluene/Cyphos 110 and toluene/aph4-cph12 solutions by use of the oxidation current of ferrocene $(\mathrm{Fc})$ to ferrocenium $\left(\mathrm{Fc}^{+}\right)$according to the following scheme: $\quad F c \rightleftarrows \mathrm{Fc}^{+}+e^{-}$

This system was chosen because the electrochemical kinetics of $\mathrm{Fc}_{\mathrm{Fc}}{ }^{+}$has been investigated in several polar organic liquids for which it serves as a reference redox system in the presence of ionic liquid as supporting electrolyte [20,31].

In order to overcome the low conductivity of the solutions, a special electrode arrangement has been used in this work and was described elsewhere [20]; it consisted of three electrodes among which two platinum wires $(0.5 \mathrm{~mm})$ embedded in a Bakelite resin shaped as a rotating rod. One electrode was positioned at the rotation axis and served as working electrode and the other one was in its close vicinity serving as pseudo reference electrode. The special electrode arrangement required the use of a rotating contactor (supplier TACUSSEL, EAD Pt/Pt model) with two independent solid contacts. The rotating disk electrode rotation speed $(\Omega)$ has been varied between 0 and $1200 \mathrm{rpm}$. The system was completed with a platinum grid of large area serving as counter electrode. The solution volume was about $20 \mathrm{~mL}$ and the temperature was set at $(35 \pm 0.2){ }^{\circ} \mathrm{C}$.

Prior to the measurements, the working electrode surface was polished with fine emery paper (grade 2400), carefully rinsed with distilled water and dried.

Electrochemical experiments combined current-potential (I-V) curves and Electrochemical Impedance Spectroscopy diagrams. I-V curves were carried out under potentiokinetic conditions at a scan rate of $20 \mathrm{mVs}^{-1}$ or in quasi steady-state conditions with potential steps of $50 \mathrm{mV}$, the measurements being taken after current stabilization. Impedance measurements have been performed between $100 \mathrm{kHz}$ and $100 \mathrm{mHz}$ with 10 points per frequency decade and 
a signal amplitude of $100 \mathrm{mV}$ rms which allowed fulfilling linearity conditions due to the high electrolyte resistance value. Measurements were carried out using an AUTOLAB interface. Impedance data have been analyzed using a home-made software (SIMAD) allowing fitting both frequency-dependent analytical expressions or equivalent electrical circuits composed of discrete elements as resistances, capacitances, inductances or diffusion impedance.

\section{Results and discussion}

\subsection{Electrochemical measurements}

\subsubsection{Steady-state data in toluene/ionic liquid with and without EHUT}

(i) Cyphos 110.

Measurements were first performed in toluene/Cyphos110 solutions containing only Fc at concentrations of $1 \mathrm{mM}, 0.5 \mathrm{mM}$ or $0.2 \mathrm{mM}$ at $\mathrm{T}=35^{\circ} \mathrm{C} .10 \mathrm{~g} / \mathrm{l}$ EHUT were further added to the $1 \mathrm{mM}$ solution. Figures $2(\mathrm{a}, \mathrm{b}, \mathrm{c})$ ) show a typical aspect of I-V curves for different rotation speeds obtained with Cyphos $110(0.1 \mathrm{M})$ and Fc concentrations of . 0.2, 0.5, and 1 $\mathrm{mM}$ respectively. Selecting several Fc concentrations allowed a better approach of the kinetical parameters of $\mathrm{Fc}$ oxidation and enabled to complete the kinetical analysis already carried out in [20] with aph4-cph12, the other ionic liquid. In Figure 2d, I-V curves in the presence of $10 \mathrm{~g} / \mathrm{L}$ of added EHUT are reported.

\section{$<$ Figure $2>$}

One can observe that a quasi horizontal plateau current is defined over several hundreds of $\mathrm{mV}$ for the lower two $\mathrm{Fc}$ concentrations $(0.2$ and $0.5 \mathrm{mM})$. It corresponds to diffusionconvection controlled conditions, the current increasing with the disk rotation speed. 
The I-V curves for the $1 \mathrm{mM} F c$ concentration display otherwise a slope immediately after the onset of a plateau current (Figure 2c).

This slope can be presumably ascribed to parasitic faradaïc currents due for instance to residual water within the ionic liquid or to the ionic liquid itself. Water purposely added to the toluene/ionic liquid mixture till $100 \mathrm{ppm}$ in the absence of Fc does not substantially increase the current (not shown). The slope appears to be steeper in the presence of EHUT (Figure 2d): This compound is not electroactive in the explored potential domain but brings another source of parasitic current, which explains the steeper slopes when it is added. However, an attempt to correct the I-V curves from the parasitic currents is questionable because the potentials reference is different between the measurements with $\mathrm{Fc}$ (and therefore determined by the $\mathrm{Fc} / \mathrm{Fc}^{+}$potential) and without it.

The onset of the diffusion plateau with potential substantially increases with the rotation speed (about $+1{\mathrm{~V} / \mathrm{Fc} / \mathrm{Fc}^{+}}^{+}$at $0 \mathrm{rpm}$ and shifted to about $+3 \mathrm{~V} / \mathrm{Fc}{ }^{+}{ }^{+}$at $1000 \mathrm{rpm}$ ) for the $1 \mathrm{mM} \mathrm{Fc}$ concentration which is a consequence of the large value of the ohmic drop resistance (see further with the Electrochemical Impedance Spectroscopy measurements). As a consequence, the existence of this large ohmic drop resistance forbids performing additional measurements with higher Fc concentrations since they would result in a significant shift of the overpotential necessary for reaching the diffusion plateau, then exceeding the limits of the potential range of the potentiostat. However, in our previous paper, it has been possible to run such an analysis even with $10 \mathrm{mM} \mathrm{Fc}$ concentration since the use of an higher amount of ionic liquid allowed to reduce the resistance value. Therefore $\mathrm{k}_{0}$ values measured in this work have been compared to the previous ones [20]. In the present study, since we mainly focused on the analysis of the mass transport data for understanding the viscoelastic properties of the solution, the choice of concentrations of $1 \mathrm{mM}$ and below for $\mathrm{Fc}$ and $0.25 \mathrm{~mm}$ for the disk radius (r) were the best compromise. 
The values of the plateau current, $I_{P}$, measured in Figure 2 have been plotted as a function of the square root of the angular disk velocity $\Omega^{1 / 2}$ in Figure 3 . The resulting linear variation $I_{P}=$ $\alpha+\beta \Omega^{1 / 2}$ fully agrees, for the three Fc concentrations, for the part $\beta \Omega^{1 / 2}$ with the Levich equation [32]: $I_{L}=0.62 n c_{\infty} F D^{2 / 3} v^{-1 / 6} \Omega^{1 / 2} A$.

Where $\mathrm{n}$ is the number of exchanged electrons (equals to 1 here), $c_{\infty}$ is the redox concentration (in mol cm${ }^{-3}$ ), $F$ is the Faraday number $(96485 \mathrm{C}$ ), $v$ is the kinematic viscosity (in $\left.\mathrm{cm}^{2} \mathrm{~s}^{-1}\right), D$ is the diffusion coefficient $\left(\right.$ in $\mathrm{cm}^{2} \mathrm{~s}^{-1}$ ) and $A$ is the electrode area $\left(\right.$ in $\mathrm{cm}^{2}$ ).

The positive intercept, $\alpha$, of the curves extrapolated to $\Omega=0$ is indicative of the presence of a parasitic current which does not depend on convection.

\section{$<$ Figure 3 >}

The $I_{p}$ currents determined for Fc oxidation at $1 \mathrm{mM}$ concentration in Cyphos 110 (0.075 and $0.085 \mathrm{M}$ ) or in Cyphos 110/EHUT mixtures display also a linear dependence on $\Omega^{1 / 2}$ (not shown). $\alpha$ and $\beta$ values have been reported in table 1 as well as both dynamic $(\eta)$ and kinematic $(v)$ viscosities for the different mixtures. Table 1 also reports the Fc diffusion coefficient $(D)$ and the Schmidt number $\mathrm{Sc}=v / D$ values. The mixtures without EHUT show higher diffusivities ranging from 3 to $510^{-5} \mathrm{~cm}^{2} \mathrm{~s}^{-1}$, slightly depending on the Cyphos110 concentration, whereas in the presence of EHUT, diffusivity decreases, because of an increase in viscosity, according to the Stokes-Einstein relation. In ref [20], Fc diffusivity was measured around $1.4310^{-5} \mathrm{~cm}^{2} \mathrm{~s}^{-1}$ at $22{ }^{\circ} \mathrm{C}$.

To ensure that mass transport was convection-diffusion controlled even at the lower rotation speed, we have evaluated the Peclet number $(\mathrm{Pe})$. The latter is a dimensionless parameter which characterizes the ratio of convective to diffusion transport. $\mathrm{Pe}=\mathrm{Re}$. Sc where $\mathrm{Re}$ is the Reynolds number $\left(\operatorname{Re}=\Omega r^{2} / v\right)$. Then $\mathrm{Pe}=\Omega \mathrm{r}^{2} / \mathrm{D}$. When $\mathrm{Pe}>>1$, the transport is dominated 
by forced convection. For $\Omega \sim 10 \mathrm{rad} \mathrm{s}^{-1}, \mathrm{D} \sim 310^{-5} \mathrm{~cm}^{2} \mathrm{~s}^{-1}$ and $\mathrm{r}=0.025 \mathrm{~cm}, \mathrm{Pe} \sim 200$ which excludes the influence of natural convection even at this low rotation speed.

It is noteworthy that the fluctuations of the current as well as the drop of its mean value above a critical angular velocity that are both observed in the case of wormlike micelles in aqueous medium $[16,17]$ as a signature of a viscoelastic character of the fluid, do not exist in the present conditions $\left(0.075\right.$ to $0.1 \mathrm{~mol} . \mathrm{L}^{-1}$ Cyphos 110 at $\left.35^{\circ} \mathrm{C}\right)$. I-V curves at Cyphos 110 concentrations below $0.075 \mathrm{~mol} \mathrm{~L}^{-1}$ could not be exploited because the diffusion plateaus were shifted to higher overpotentials and could not be observed.

(ii) aph4-cph12.

I-V curves have been plotted in the same conditions as above in terms of Fc concentration and temperature, with and without EHUT and for three ionic liquid concentrations: 0.03, 0.04 and $0.05 \mathrm{~mol} \mathrm{~L}^{-1}$. Diffusion plateaus were present even for the lowest ionic liquid concentration investigated.

Levich behavior $\left(\mathrm{I}_{\mathrm{L}} \propto \Omega^{1 / 2}\right)$ was confirmed for the three concentrations. $\alpha, \beta$, D and Sc values in the absence of EHUT have been reported in table 1. The lower ionic liquid concentrations explain the low values computed for the Schmidt number.

In the presence of EHUT, the Levich behavior was still observed but only at the lower rotation speed. Quite remarkably, for a critical rotation speed, the current slightly decreased, deviating from the Levich line, and intense fluctuations of the current arose and persisted till the higher rotation speed of $2000 \mathrm{rpm}$ (see Figure 4 in which the grey domains depict the extent of the current fluctuations).

\section{< Figure 4 >}


When decreasing the rotation speed, the same current values as those found when it was increased were measured. Furthermore, the fluctuations ceased at the same critical rotation speed i.e. around $300 \mathrm{rpm}$ for $0.03 \mathrm{~mol} \mathrm{~L}^{-1}$ and $500 \mathrm{rpm}$ for $0.04 \mathrm{~mol} \mathrm{~L}^{-1}$. Lastly, at $0.05 \mathrm{~mol}$ $\mathrm{L}^{-1}$ there is no more transition and the Levich regime is valid till $2000 \mathrm{rpm}$.

Therefore, apart from the hysteresis which was not observed here, the supramolecular polymer solution exhibits the same features with a rotating disk electrode - i.e. current drop and strong fluctuations of the diffusion current- as polymer and surfactant solutions do. In all cases, this could be related to the elongated nature of the objects in the presence of flow with an elongational component. For the rotating disk electrode, the maximum value of the elongational strain is of the order of $\Omega$ at the outer limit of the hydrodynamic boundary layer [15].

For polymer chains, this behavior has been associated to the coil $\leftrightarrow$ stretch transition predicted by De Gennes [33] and the critical rotation speed was related to a Deborah number $D e$ of the order of 1 ( $D e$ being the ratio of a characteristic time of the polymer chain-precisely the Zimm relaxation time-and a characteristic time of the flow, here $\Omega^{-1}$ ). Therefore, the higher the molecular weight (and thus, the longer the chain), the lower the critical rotation speed.

\section{$<$ Figure 5 >}

Similarly, such a first order transition with the onset of mass transfer fluctuations was observed for drag reducing cationic surfactant solutions [15-17]. Obviously the relaxation time deduced from the condition $D e \sim 1$ cannot be meant to represent a Zimm relaxation time for surfactant solutions. It has been independently established that the drag reduction efficiency of these solutions increases when the counter ion to surfactant concentrations ratio, 
$\zeta$, increases. These solutions present a shear thinning behavior with a characteristic time (defined from rheological measurements by the intersection of the low shear rate pseudo Newtonian plateau and the high shear rate power law regime) which increases with $\zeta$ [34]. Structural changes were also observed with the increase of $\zeta$, in particular an elongation of the worm like micelles (as evidenced from tapping mode AFM in air on a surface having weak surface interaction with the lying micelles [35]) or a transition between sparse individual micelles at low $\zeta$ and entangled ones at higher $\zeta$ values their number and length being increased [36]. The characteristic time deduced from the electrochemical data could result from the geometric average of two times, a time corresponding to the scission of the micelles and a time corresponding to their reptation [7]. Some of these analogies exist for the supramolecular polymer solutions [37] and will be addressed with the rheological and light scattering data further reported.

Concurrently, the viscoelasticity of the EHUT solutions can be qualitatively assessed by observing the effect of the rotation of a rod in a $0.03 \mathrm{~mol} \mathrm{~L}^{-1}$ concentrated solution (Figure 5): one can see that the fluid rises up instead of forming a vortex around it, evidencing a Weissenberg effect, characteristic of the normal stresses difference.

\subsubsection{Electrochemical Impedance Spectroscopy data}

(i) Cyphos 110

The same nine different mixtures as those used for the steady-state measurements, the characteristics of which are reported in table 1, have been investigated by electrochemical impedance spectroscopy measurements and the diagrams were recorded at the half wave potential. All impedance diagrams (as for example that displayed in Figure 6a for Cyphos 110 $(0.1 \mathrm{M}) /$ toluene/1 $\mathrm{mM}$ ferrocene mixture) contain a large semicircle capacitive loop in the high frequency range and a diffusion convective loop in the low frequency range. The high 
frequency loop does not correspond, as usual, to the parallel association of the charge transfer resistance and the double layer capacitance as explained later. In fact, the loop corresponding to charge transfer at medium frequency is hardly detectable here as it was in [20] for the aph4cph12 because of the lower Re value in this latter case. Here, it is located at the transition between the high frequency loop and the diffusion loop and could be evaluated only by the fitting procedure.

In addition, in the very low frequency range, the diagrams obtained for the $\mathrm{Fc}$ concentration of $1 \mathrm{mM}$ display an inductive loop irrespective of the Cyphos concentration (e.g. see Figures 6a-b). Conversely, this loop does not exist at lower Fc concentrations (e.g. Figure 6c).

The existence of this very low frequency inductive loop could result from the precipitation at the electrode surface of ferrocenium whose solubility appeared to be quite low (around 0.5 $\mathrm{mM})$ as measured in aph4-cph12 [20].

These features were accounted for by using two electrical equivalent circuits including a charge transfer resistance $R_{t}$ for the electron exchange in ferrocene oxidation, and a diffusion impedance $Z_{d}$ for the diffusion-convective transport of ferrocene from the bulk solution to the electrode surface. The diameter of the large high frequency capacitive loop corresponds to the electrolyte resistance due to the ionic liquid, on which a geometric capacitance was set in parallel due to the possible combined effects of the volume capacitance of the solution and/or artefacts resulting from the close vicinity of the wiring for the reference and working electrodes and a parasitic capacitance due to the potentiostat. This large high frequency loop is generally not visible in aqueous solutions because $R_{e}$ values are usually much lower. This interpretation was supported by the presence of the same loop in the absence of redox species (results not shown). The inductive behavior was taken into account in the relevant electrical equivalent circuit (Figure 7b) by adding in parallel to $Z_{d}$ an adsorption resistance $R_{a d}$ in series with an inductance $L$. $Q$, a constant phase element and $\mathrm{n}$ the associated exponent, replacing 
the usual double layer capacitance, is put in parallel to $R_{t}$ and defines a constant phase element impedance as:

$$
Z_{C P E}=\frac{1}{Q(j \omega)^{n}}
$$

The resulting electrical equivalent circuits are shown in Figure 7a-b

It must be noted that $Z_{d}$ is not included in the "Faradaïc" branch with $R_{t}$ as usually done in the Randles circuit because the presence of the constant phase element on parallel to $Z_{d}$ results in irrealistically large Sc values. In fact the large $R_{d}$ values combined with the equivalent double layer capacitance $C_{e q}$ (see further) provide characteristic frequencies in the range of the characteristic convective diffusion frequencies.

\section{$<$ Figure $6>$}

\section{$<$ Figure $7>$}

The simulated diagrams using the electrical equivalent circuits of figure 7 have been fitted to the experimental diagrams to deduce the different parameters values. In general, if the overall quality of the fitting procedure is satisfactory with a quality factor $\chi$ around 1 by assigning a random relative error of $1 \%$ on the modulus in the whole frequency range, one must be aware that at low frequency, the scattering in the data entails a poorer determination of the "faradaiic" parameters (i.e., $\left.R_{t}, Z_{d}, R_{a d}, L\right)$ due to the large $R_{e}$ value. The quality of the fit is in the same range for the mixtures with or without EHUT which involves that the level of fluctuations of the limiting diffusion current is similar, and this excludes the onset of large random fluctuations as those observed with surfactants displaying viscoelasticity in aqueous solutions [16]. 
The Schmidt number values are rather scattered but are evenly distributed around the value originating from steady-state measurement. Taking an average of the steady-state and impedance measurements provides a value of $\mathrm{D} \sim 410^{-5} \mathrm{~cm}^{2} \mathrm{~s}^{-1}$.

Regarding other parameters such as $R_{t}, R_{e}, Q, n$, they can be used to derive two quantities: the heterogeneous rate constant $\mathrm{k}_{0}$ of the $\mathrm{Fc} / \mathrm{Fc}^{+}$reaction and the equivalent double layer capacitance $C_{e q}$. According to the work of Brug et al. [38]:

$$
C_{e q}=Q^{1 / n}\left(R_{e}^{-1}+R_{t}^{-1}\right)^{n-1 / n}
$$

and $k_{0}$ value can be determined as defined in [20]:

$$
k_{0}=\frac{R T}{n^{2} F^{2} A R_{t}\left(C_{o x}^{0}\right)^{1 / 2}\left(C_{r e d}^{0}\right)^{1 / 2}}
$$

Interfacial concentrations can be expressed as functions of the bulk concentrations in simple cases. For example, when only one species is present in solution, then, as in [20], the measurement at the half wave potential (here for the oxidation step) yields the condition $C_{\text {red }}^{0}=C_{o x}^{0}=C_{r e d}^{\infty} / 2$

Also, when the two species are at equal concentrations, and the measurement is done at the half wave of the oxidation step, then:

$$
C_{r e d}^{0}=C_{r e d}^{\infty} / 2 \text { and } C_{o x}^{0}=3 C_{r e d}^{\infty} / 2
$$

$k_{0}$ values given in table 2, except for one value corresponding to $\operatorname{Cyphos}(0.1 \mathrm{M}) / \mathrm{Fc}(0.2 \mathrm{mM})$, are quite well gathered around $210^{-3} \mathrm{~cm} \mathrm{~s}^{-1}$, close to the value which was found in [20] for aph4-cph12. So, it can be assumed following the conclusions of Fontaine et al. [39] for Fc oxidation in Ethyl methyl midazolium/TFSI that the electron transfer dynamics should be strongly influenced by the counter ion motion being highly slowed down. 
$C_{e q}$ values conversely are somehow larger (centered around $10 \mu \mathrm{F} \mathrm{cm}^{-2}$ ) and it could be thought that in that potential range, the specie most likely to be adsorbed, and playing the role of the compact layer, would be hexafluorophosphate anion which is much smaller than aph4cph12 investigated in [20].

\section{(ii) aph4-cph12}

Some electrochemical impedance spectroscopy measurements have been performed for the three lowest aph4-cph12 concentrations $\left(0.03 \mathrm{~mol} \mathrm{~L}^{-1}\right.$ to $\left.0.05 \mathrm{~mol} \mathrm{~L}^{-1}\right)$. The low conductivity of the solutions renders the fitting procedure more delicate and the characterization of the medium frequency and very low frequency parameters is therefore poorly accurate. The values have also been reported in table 2 for the $0.03 \mathrm{~mol} \mathrm{~L}^{-1}$ concentration in the absence of EHUT. Sc value is in the same range as that originating from steady-state data and $\mathrm{k}_{0}$ is of the same order of that given in [20] for higher ionic liquid concentrations. In addition, in agreement with steady state measurements, low frequency data appears strongly scattered when fluctuations are present, which obviously affects $Z_{d}$.

\section{2 viscosity measurements}

Figure 8 represents the viscosity of EHUT solution at $10 \mathrm{~g} / \mathrm{L}$ in toluene with various amounts of Cyphos 110 as function of shear rate. The rheograms are typical of shear thinning fluids. Without Cyphos 110, EHUT solution exhibits a high zero shear viscosity, about $10^{5}$ times that of toluene, due to the self assembly of EHUT molecules into supramolecular structures through hydrogen bonding [4].

With increasing the amount of Cyphos 110, the zero shear viscosity sharply decreases. In addition, the relaxation time taken as the reciprocal of the crossing value between the pseudo Newtonian plateau for low shear rate values and the power law domain, sharply decreases to 
very low values and can no more be measured in the covered shear rate range for the highest concentrations. These results reflect the so called chain stopper effect of Cyphos 110 on EHUT association [37, 40, and 41].

For achieving a proper comparison between these flow measurements and the RDE geometry, in the latter case, the shear rate $\dot{\gamma}=\left.\frac{\partial V_{p}}{\partial y}\right|_{y=0}$ was evaluated at the periphery of the disk electrode from the component parallel to the disk plane of the velocity vector, $V_{P}$, The shear rate domain covered $\left(\dot{\gamma}_{\min }, \dot{\gamma}_{\max }\right)$ in the electrochemical experiments ranged from about15 to $150 \mathrm{~s}^{-1}$ for $\Omega$ varying between 100 and $1000 \mathrm{rpm}$.

Therefore, at the shear rate applied by the electrode (between $\dot{\gamma}_{\min }$ and $\dot{\gamma}_{\max }$ ) the regime is Newtonian beyond $0.03 \mathrm{M}$ of Cyphos 110. Above this concentration the solutions of EHUT are still viscous which explains the lower current limit actually observed in the presence of bis-urea.

\section{$<$ Figure $8>$}

\section{$<$ Figure 9 >}

By opposition, viscosity measurements with the aph4-cph12 (see Figure 9) show conversely that for the concentration range investigated, the characteristic relaxation times can be measured. The critical shear rate increases when increasing the aph4-cph12 concentration. Therefore the characteristic relaxation time decreases accordingly. The values of 8 and $25 \mathrm{~s}^{-1}$ for respectively 0.03 and $0.04 \mathrm{~mol} \mathrm{~L}^{-1}$ are in rough agreement with 30 and $50 \mathrm{~s}^{-1}$ corresponding to the critical velocities given by the electrochemical steady- state data despite the fact that the flow geometries are pretty different. 


\subsection{Light scattering measurements}

The dynamic correlation length $\xi$, measured by dynamic light scattering as a function of the concentration of Cyphos 110 is shown in Figure 10. For a toluene/EHUT (10 g/L) mixture, $\xi=4.4 \mathrm{~nm}$ which is typical of the semi dilute regime and represents the pseudo mesh size of an entangled network. When Cyphos 110 is added, the dynamic correlation length sharply increases to $12 \mathrm{~nm}$ for $0.01 \mathrm{~mol} \mathrm{~L}^{-1}$ which actually means that the entangled network is broken. By further increasing the Cyphos 110 concentration, $\xi$ decreases evidencing the chain stopper effect of Cyphos anion on the supramolecular structure of EHUT. At $0.075 \mathrm{M}$ of Cyphos $110, \xi=6.5 \mathrm{~nm}$ and the viscosity of the mixture is about $1.6 \mathrm{mPa} . \mathrm{s}$ which is the signature of the presence of supramolecular aggregates based on EHUT however too short for providing any viscoelastic character to the solutions.

$\xi$ values measured for aph4-cph12 RTIL in the concentration range investigated for electrochemical and viscosity measurements are reported in the same Figure 11. By opposition, $\xi$ remains constant and equal to $4 \mathrm{~nm}$ indicating that the entangled network is not broken in the presence of this ionic liquid. Therefore, the supramolecular aggregates are entangled and provide a viscoelastic character to the solutions. It can be concluded that aph4cph12 has a smaller chain stopper effect than Cyphos 110.

\section{$<$ Figure $10>$}




\section{Conclusions}

This work was intended for evidencing the possible formation of reversible supramolecular structures from EHUT (2, 4-bis (2-ethylhexylureido) toluene) monomer in toluene and assessing the viscoelastic character of this solution in the presence of either of two added ionic liquids known as chain stoppers. These ionic liquids, Cyphos 110 and aph4-cph12, were based on a common phosphonium cation and two different anions, namely hexafluorophosphate and tris(pentafluoroethyl) trifluorophosphate respectively. To this end, electrochemical, rheological and light scattering methods were combined.

Electrochemical methods, based on the analysis of current potential curves and of Electrochemical Impedance Spectroscopy diagrams were conducted with a rotating disk electrode, a geometry containing an elongational component thus able to trigger viscoelastic effects.

From the analysis of the limiting diffusion plateau, diffusion coefficients of ferrocene in those mixtures could be measured. It was found that the presence of EHUT decreased this value because of the viscosity increase. In the case of the Cyphos 110, the diffusion current followed the Levich law over the whole angular velocity range as for a Newtonian fluid, thus evidencing the absence of any viscoelastic character for these solutions. By opposition, in the presence of aph4-cph12, a departure from the Levich law together with strong fluctuations of the current allowed to assign a viscoelastic character to the solutions.

The electrochemical impedance spectroscopy diagrams showed the presence of an inductive effect revealing an adsorption of the ionic liquid fluctuating with potential and likely due to the anion. The analysis of the diagrams with frequency allowed measuring the heterogeneous rate constant of the $\mathrm{Fc} / \mathrm{Fc}^{+}$system in the range of $210^{-3} \mathrm{~cm} \mathrm{~s}^{-1}$ for the two ionic liquids, close to a value previously measured in the aph $4 \mathrm{cph} 12$ at higher concentrations. 
From the rheological data it was deduced that in the presence of EHUT a characteristic time was measurable only for the aph4-cph12 and decreased when increasing the concentration of ionic liquid; this feature was in qualitative agreement with the characteristic time deduced from the critical velocity marking the onset of strong fluctuations and departure from the Levich law. The light scattering data indicated that, while in the absence of ionic liquid the EHUT supramolecular polymer formed an entangled network, this structure was broken when the concentration of Cyphos 110 is higher than $0.01 \mathrm{~mol} \mathrm{~L}^{-1}$, whereas it persisted till $0.04 \mathrm{~mol}$ $\mathrm{L}^{-1}$ for aph4-cph12. The latter one is thus a less efficient chain stopper than the former. It could be also inferred that the length of the individual chains measured in the investigated concentration range was too short to give rise to any viscoelastic effects.

\section{Acknowledgements}

The authors want to acknowledge the financial support of the PHC Tassili (project 13 MDU 893). They also thank S. Catrouillet for supplying them with EHUT. 


\section{References}

[1] A.W. Bosman, R.P. Sijbesma, and E.W.Meijer. Supramolecular polymers at work, Mater. Today, 7 (2004) 34.

[2] E. Sabadini, K. R. Francisco, and L. Bouteiller, Bis-Urea-Based Supramolecular Polymer: The First Self-Assembled Drag Reducer for Hydrocarbon Solvents, Langmuir 26, 3 (2010) 1482.

[3] F. Lortie, S. Boileau, L. Bouteiller, C. Chassenieux, B. Deme, G. Ducouret, M. Jalabert, F. Laupretre, and P. Terech, Structural and Rheological Study of a Bis-urea Based Reversible Polymer in an Apolar Solvent, Langmuir 18 (2002) 7218.

[4] O. Colombani and L. Bouteiller, Selective synthesis of non-symmetrical bis-ureas and their self-assemblyw, New J. Chem. 28 (2004) 1373.

[5] J. van der Gucht, M. Lemmers, W. Knoben, N. A. M. Besseling, and M. P. Lettinga, Multiple Shear-Banding Transitions in a Supramolecular Polymer Solution, Phys. Rev. Lett., 2006

[6] M. Bellot and L. Bouteiller, Thermodynamic Description of Bis-urea Self-Assembly: Competition between Two Supramolecular Polymers, Langmuir 24 (2008) 14176.

[7] M.E. Cates and S.J. Candau, statics and dynamics of worm-like surfactant micelles, J. Phys. Condens. Matter 2 (1990) 6869.

[8] J. Yang, Viscoelastic wormlike micelles and their applications, Current Opinion in Colloid \& Interface Science 7 (2002) 276.

[9] J. Myska, J.J. Zakin, Differences in the flow behaviors of polymers and surfactant dragreducing additives, Ind. Eng. Chem. Res. 38 (1997) 5483.

[10] Y. Hu, E. F. Matthys, Rheological and rheo-optical characterization of shear-induced structure formation in a nonionic drag-reducing surfactant solution, J. Rheolog. 41, 1 (1997) 151.

[11] E. Bilgen, On the orifice flow of dilute polymer solutions, Journal de Mécanique, 12 (1973) 375-391.

[12] Ouibrahim A., Rheology of polymer solutions in laminar capillary tube flows Physics of Fluids, 21 (1978) 4-8.

[13] Fruman D. H., Tulin M. P., Dilute polymer flows at high strain rates: A correlation of data, Physics of Fluids, 21 (1978).1896-1899. 
[14] Halliwell N. A. , Lewkowicz A. K. , Investigation into the anomalous behavior of Pitot tubes in dilute polymer solutions, Physics of Fluids, 18 (1975) 1617-1625.

[15] C. Deslouis, Microscopic aspects of surfactants action on flow induced corrosion, Electrochem. Acta, 48 (2003) 3279.

[16] M.S. Boutoudj, A. Ouibrahim, and C. Deslouis, Mass transfer in a laminar elongational flow of a drag reducing surfactant, J. Non-Newtonian Fluid Mech. 103 (2002) 141.

[17] L. Chaal, M.S. Boutoudj, A. Ouibrahim, B. Saidani, R.P. Nogueira, C. Deslouis, Mass transfer rate and conductivity instabilities in surfactant solutions submitted to a laminar elongational flow, J. Non-Newtonian Fluid Mech. 121 (2004) 143.

[18] L. Chaal, B. Albinet , C. Deslouis , Y.T. Al-Janabi , A. Pailleret , B. Saidani , G. Schmitt, Wall shear stress mapping in the rotating cage geometry and evaluation of drag reduction efficiency using an electrochemical method, Corrosion Science 51 (2009) 1809.

[19] Deslouis C., Tribollet B., Cressely R., Hocquart R., Electrochemical and optical studies of a stable to unstable transition in a polymer solution flowing close to a rotating disk, Rheolog. Acta, 20 (1981) 29.

[20] N. Brinis , K. Aoudia , L. Chaal, B. Saidani, C. Deslouis, Heterogeneous electron transfer and diffusivities of ferrocene/ferrocenium couple in toluene/phosphonium-based ionic liquid solutions, Journal of Electroanalytical Chemistry 692 (2013) 46.

[21] J. Zhang, A.M. Bond, Practical Considerations Associated with Voltammetric Studies in Room Temperature Ionic Liquids, Analyst 130 (2005) 1132.

[22] M. Galinski, A. Lewandowski, I. Stepniak, Ionic liquids as electrolytes, Electrochimica Acta 51 (2006) 5567.

[23] P. Hapiot, C. Lagrost, Electrochemical reactivity in room-temperature ionic liquids, Chem. Rev. 108 (2008) 2238.

[24] M. Hadi Ghatee, M. Zare, A. Reza Zolghadr, F. Moosavi, Temperature dependence of viscosity and relation with the surface tension of ionic liquids, Fluid Phase Equilibri 291 (2010) 188.

[25] A. Stoppa, R. Buchner, G. Hefter, How ideal are binary mixtures of room-temperature ionic liquids?, Journal of Molecular Liquids 153 (2010) 46.

[26] G. D. Allen , M. C. Buzzeo , C. Villagran, C. Hardacre , R. G. Compton, A mechanistic study of the electro-oxidation of bromide in acetonitrile and the room temperature ionic liquid, 1-butyl-3-methylimidazolium bis (trifluoromethylsulfonyl) imide at platinum electrodes,Journal of Electroanalytical Chemistry 575 (2005) 311. 
[27] N.W. Duffy, A.M. Bond, Macroelectrode voltammetry in toluene using a phosphonium phosphate ionic liquid as the supporting electrolyte, Electrochem. Commun. 8 (2006) 892.

[28] C. Comminges, R. Barhdadi, M. Laurent and M. Troupel, Determination of Viscosity, Ionic Conductivity, and Diffusion Coefficients in Some Binary Systems: Ionic Liquids + Molecular Solvents, J. Chem. Eng. Data 51 (2006) 680.

[29] S.Boileau, L. Bouteiller, F. Laupretre, F. Lortie, Soluble supramolecular polymers based on urea compounds, F. New J. Chem. 24 (2000) 845.

[30] J. Jakes Regularized Positive Exponential Sum (REPES) Program - A Way of Inverting Laplace Transform Data Obtained by Dynamic Light Scattering, Collect. Czech. Chem. Commun. 60 (1995) 1781.

[31]D. L. Boxall, J. J. O’Dea, and R. A. Osteryoung, Apparent Anomaly during Rotating Disk Voltammetry in Ionic Liquids, Journal of The Electrochemical Society 149, 11 (2002) E468.

[32] V. G. Levich, Acta Physicochim. URSS, 17, 257, (1942), Physicochemical Hydrodynamics, Prentice Hall, Inc., Englewood Cliffs, NJ 1962.

[33] P. G. de Gennes, J. Chem. Phys. 60, 5030 (1974).

[34] G.D. Rose and K.L. Foster, Drag reduction and rheological properties of cationic viscoelastic surfactant formulations, J. Non Newtonian Fluid Mech. 31 (1989) 59-85.

[35] L. Chaal, F. Pillier, B. Saidani, S. Joiret, A. Pailleret and C. Deslouis, Characterisation of counterion and surface influence on micelle formation using tapping mode atomic force microscopy in air", J. Phys. Chem. B, Vol 110 (2006)21710-21718.

[36] Wu Ge, Ellina Kesselman, Yeshayahu Talmon, David J. Hart, Jacques L. Zakin, Effects of chemical structures of para-halobenzoates on micelle nanostructure, drag reduction and rheological behaviors of dilute CTAC solutions, J. Non-Newtonian Fluid Mech. 154 (2008) 1-12

[37] G. Ducouret, C. Chassenieux, S. Martins, F. Lequeux, L. Bouteiller, Rheological characterisation of bis-urea based viscoelastic solutions in an apolar solvent, journal of colloid and interface science Journal of Colloid and Interface Science 310 (2007) 624.

[38] G. J. Brug, A.L.G. Van Den Eeden, M. Sluyters-Rehbach, J.H. Sluyters, the analysis of electrode impedances complicated by the presence of a constant phase element, J. Electroanal. Chem. 176 (1984) 295.

[39] O. Fontaine, C. Lagrost, J. Ghilane, P. Martin, G. Trippé, C. Fave, J.-C. Lacroix, P. Hapiot, H.N. Randriamahazaka, J. Electroanal. Chem. 632 (2009) 88. 
[40] T. Pinault, C. Cannizzo, B. Andrioletti, G. Ducouret, F. Lequeux, and L. Bouteiller, Anions as Efficient Chain Stoppers for Hydrogen-Bonded Supramolecular Polymers, Langmuir 25, 15 (2009) 8404.

[41] F. Lortie, S. Boileau, L. Bouteiller, C. Chassenieux, and F. Lauprétre, Chain StopperAssisted Characterization of Supramolecular Polymers, Macromolecules 38 (2005) 5283.

\section{Captions of the Figures}

Figure 1: pictures of mixtures in toluene of EHUT/Cyphos $110\left(10 \mathrm{~g} . \mathrm{L}^{-1} / 0.075 \mathrm{M}\right)$,

a) $\mathrm{T}<35^{\circ} \mathrm{C}$, b) $\mathrm{T} \geq 35^{\circ} \mathrm{C}$.

Figure 2: Current potential curves of Fc oxidation in toluene/ [Cyphos 110] 0.1M solution for different RDE rotation speeds between $100 \mathrm{rpm}$ and 1200rpm.

(a) $[\mathrm{Fc}]=0.2 \mathrm{mM}$; (b) $[\mathrm{Fc}]=0.5 \mathrm{mM}$. The plots have been recorded in quasi steady-state. (c)

$[\mathrm{Fc}]=1 \mathrm{mM}$; (d) $[\mathrm{Fc}]=1 \mathrm{mM}$ with $10 \mathrm{~g} / \mathrm{l}$ EHUT added to the solution. Plots for (c) and (d) conditions have been recorded at $20 \mathrm{mV} \mathrm{s}^{-1} ; \mathrm{T}=35^{\circ} \mathrm{C}$.

Figure 3: Limiting diffusion current vs. $\Omega^{1 / 2}$ from data in current potential curves of Figure 2, $\mathrm{T}=35^{\circ} \mathrm{C}$.

All data correspond to toluene/ Cyphos 110(0.1 $\left.\mathrm{M} \mathrm{L}^{-1}\right)$ mixtures.

$[\mathrm{Fc}]=(\boldsymbol{\square}) 1 \mathrm{mM} ;(\boldsymbol{O}) 0.5 \mathrm{mM} ;(\boldsymbol{\Delta}) 0.2 \mathrm{mM}$.

Figure 4: Limiting diffusion current vs. $\Omega^{l / 2} ; \mathrm{T}=35^{\circ} \mathrm{C}$. All data correspond to toluene/(ach4cph12(0.03 or $\left.0.04 \mathrm{ML}^{-1}\right) / 1 \mathrm{mMFc}$ mixtures. (a) $0.03 \mathrm{M} \mathrm{L}^{-1}$ ach4-cph12; (b) $0.04 \mathrm{M} \mathrm{L}^{-1}$ ach4cph12. Blank solution or with added 10 g.L L $^{-1}$ EHUT.

Figure 5: Photo of a $0.03 \mathrm{M} \mathrm{L}^{-1}$ aph4cph12 + $10 \mathrm{~g} / \mathrm{l}$ EHUT solution $(\Omega=1000 \mathrm{rpm})$ showing Weissenberg effect.

Figure 6: Impedance diagrams in Nyquist coordinates (real part/-Imaginary part) recorded at the half wave of the ferrocene oxidation. Solution: toluene, Cyphos 110;

(a) Cyphos $110(0.1 \mathrm{M})[\mathrm{Fc}]=1 \mathrm{mM}, \Omega=300 \mathrm{rpm}$; (b) Cyphos $110(0.075 \mathrm{M})[\mathrm{Fc}]=1 \mathrm{mM}, \Omega$ $=100 \mathrm{rpm}$; (c) Cyphos $110(0.1 \mathrm{M})[\mathrm{Fc}]=0.2 \mathrm{mM}, \Omega=300 \mathrm{rpm} ; \mathrm{T}=35^{\circ} \mathrm{C}$.

Figure 7: Electrical equivalent circuits used for analyzing the EIS data with or without EHUT: (a) circuit for $[\mathrm{Fc}]=1 \mathrm{mM}$; (b) circuit for $[\mathrm{Fc}]=0.2$ and $0.5 \mathrm{mM}$.

Figure 8: Influence of Cyphos 110 addition on the viscosity of EHUT solution $\left(10 \mathrm{~g} \mathrm{~L}^{-1}\right)$ in toluene at $35.0{ }^{\circ} \mathrm{C}$. 
Figure 9: Influence of ach4-cph12 addition on the viscosity of EHUT solution $\left(10 \mathrm{~g} \mathrm{~L}^{-1}\right)$ in toluene at $35.0{ }^{\circ} \mathrm{C}$.

Figure 10: The dynamic correlation length of EHUT $(10 \mathrm{~g} / \mathrm{l})$ in toluene $(+1 \mathrm{mM} \mathrm{fc})$ at $35.0^{\circ} \mathrm{C}$ as a function of the concentration of the ionic liquid. ( $\square$ ) Cyphos 110; (O) ach4-cph12. 


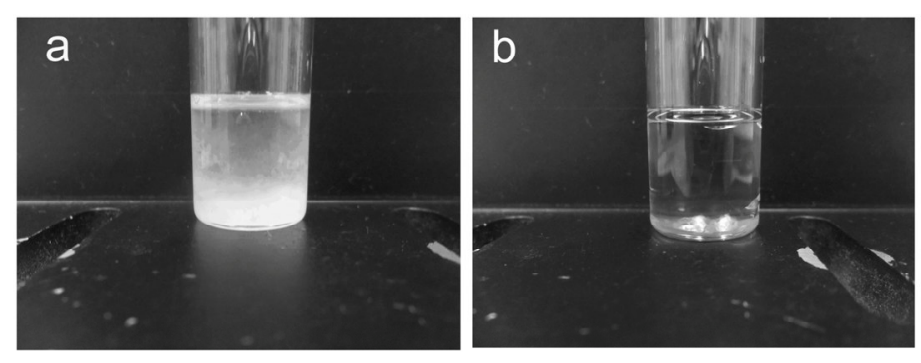

Figure 1 

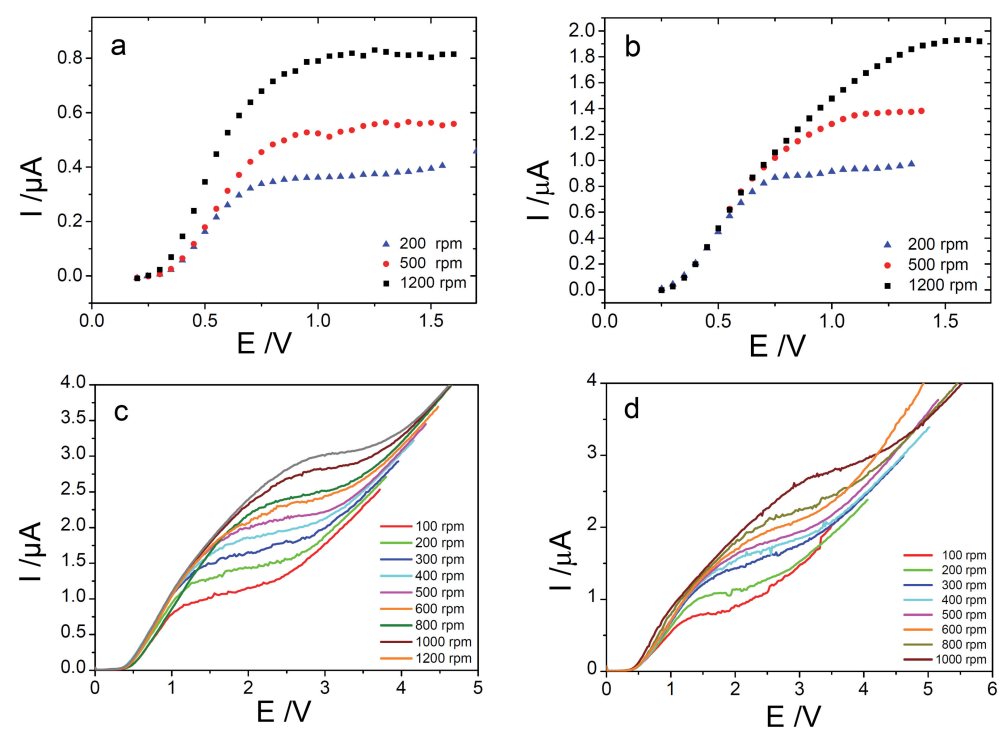

Figure 2 


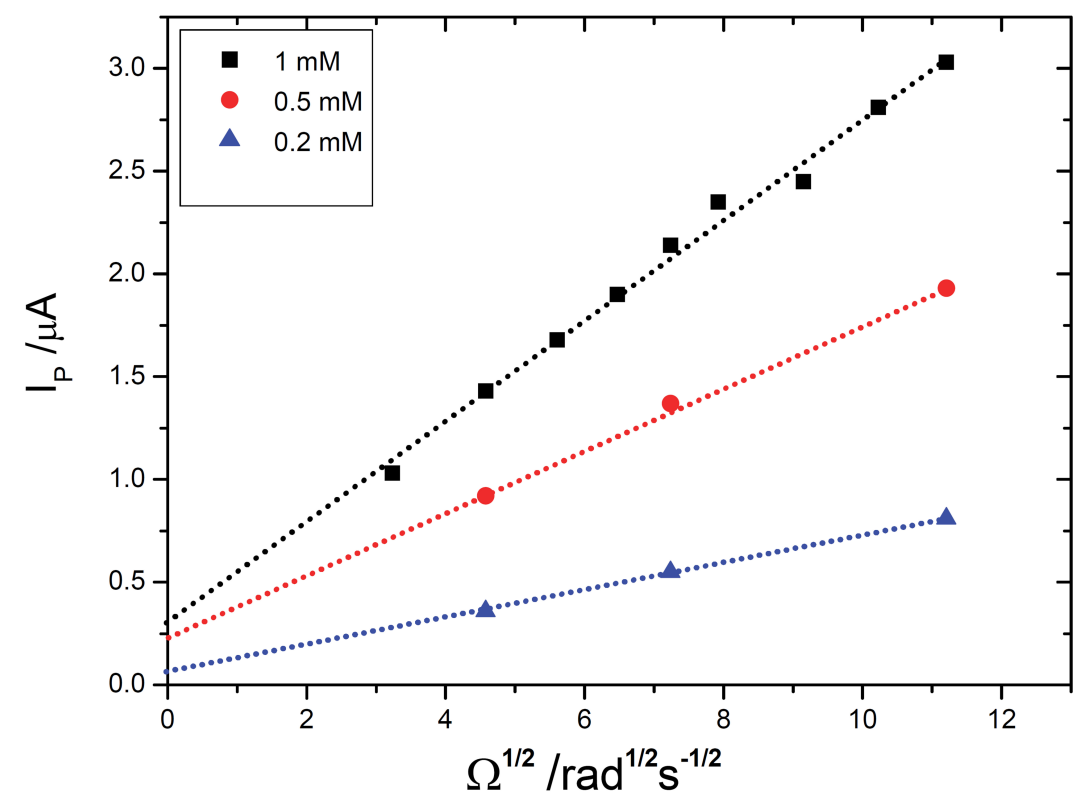

Figure 3 

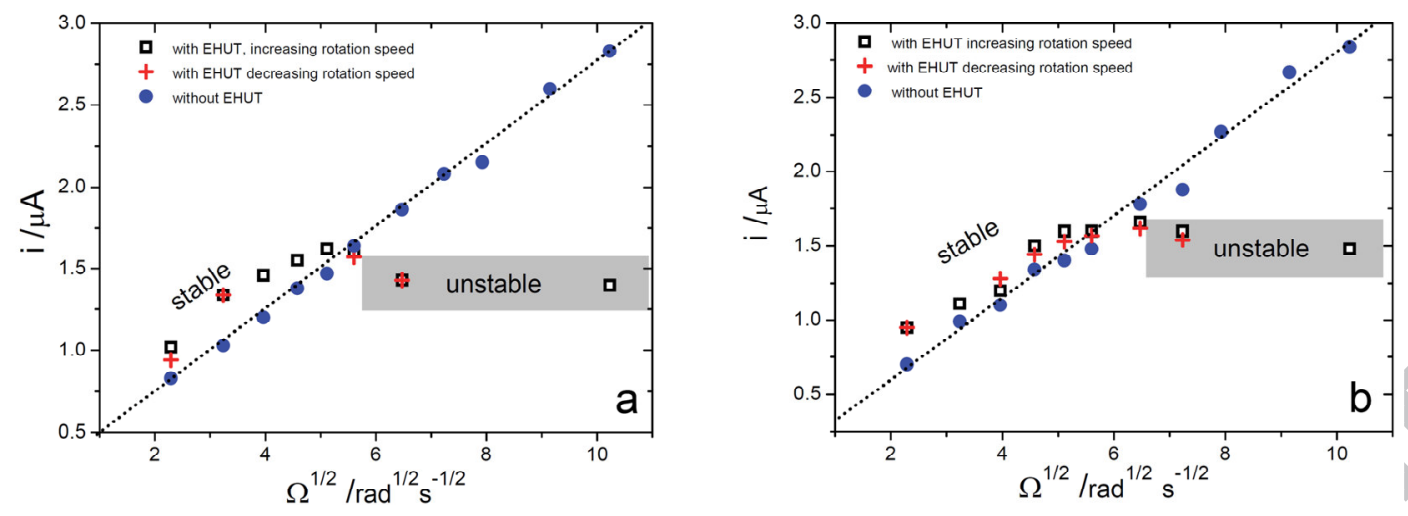

Figure 4 

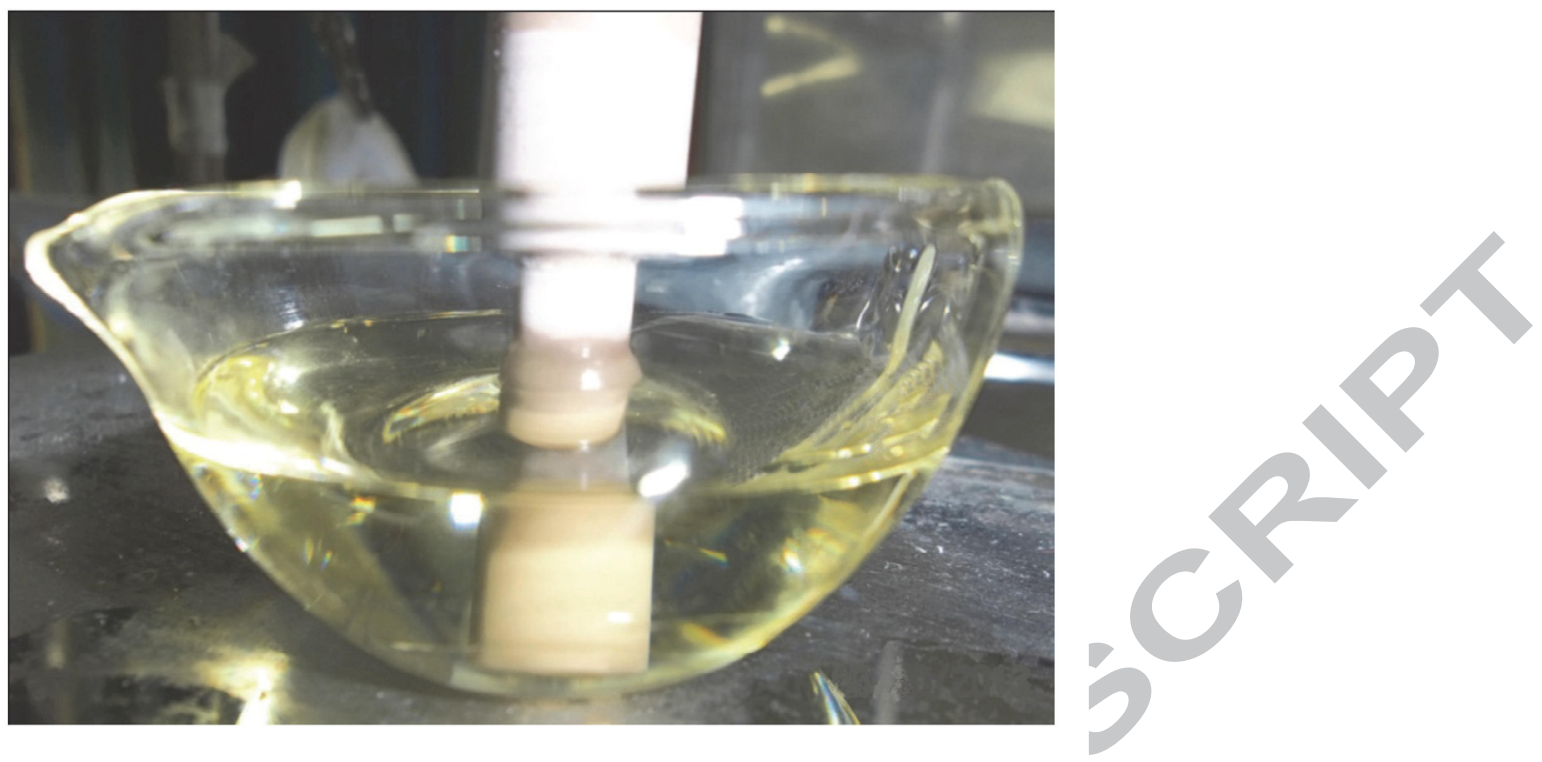

Figure 5

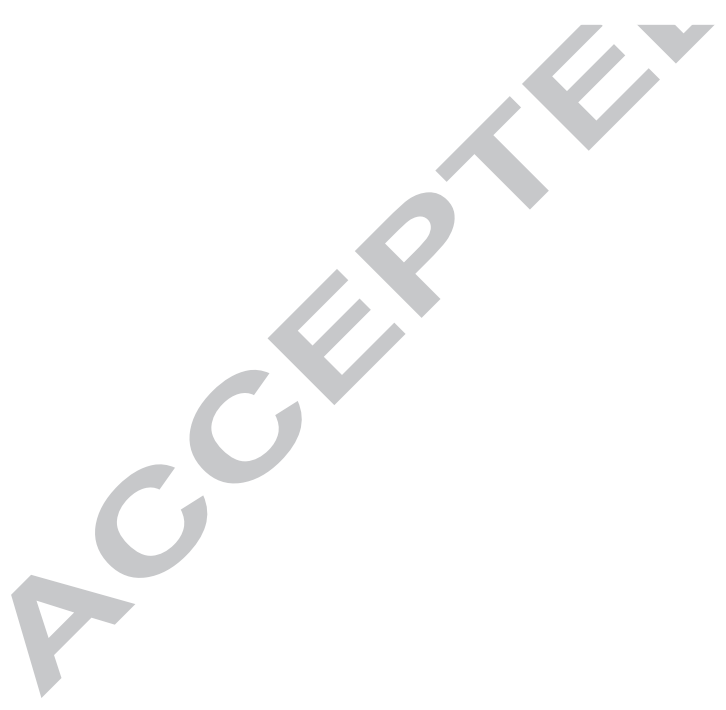



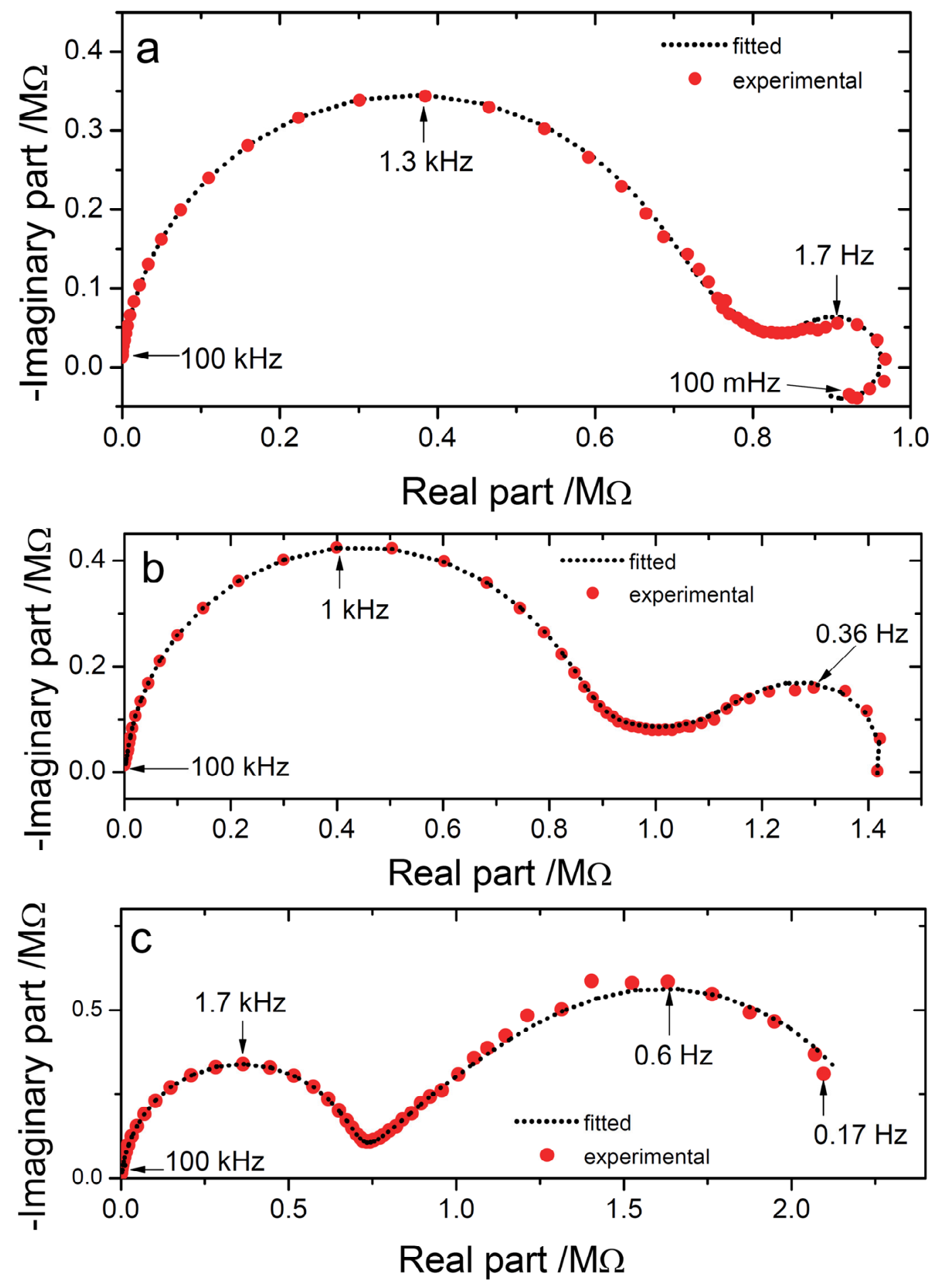

Figure 6 


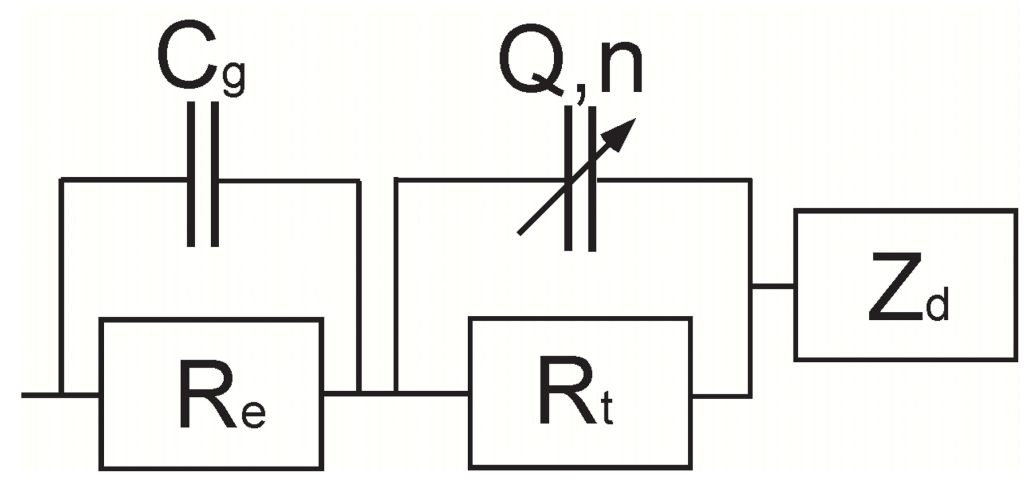

(a)

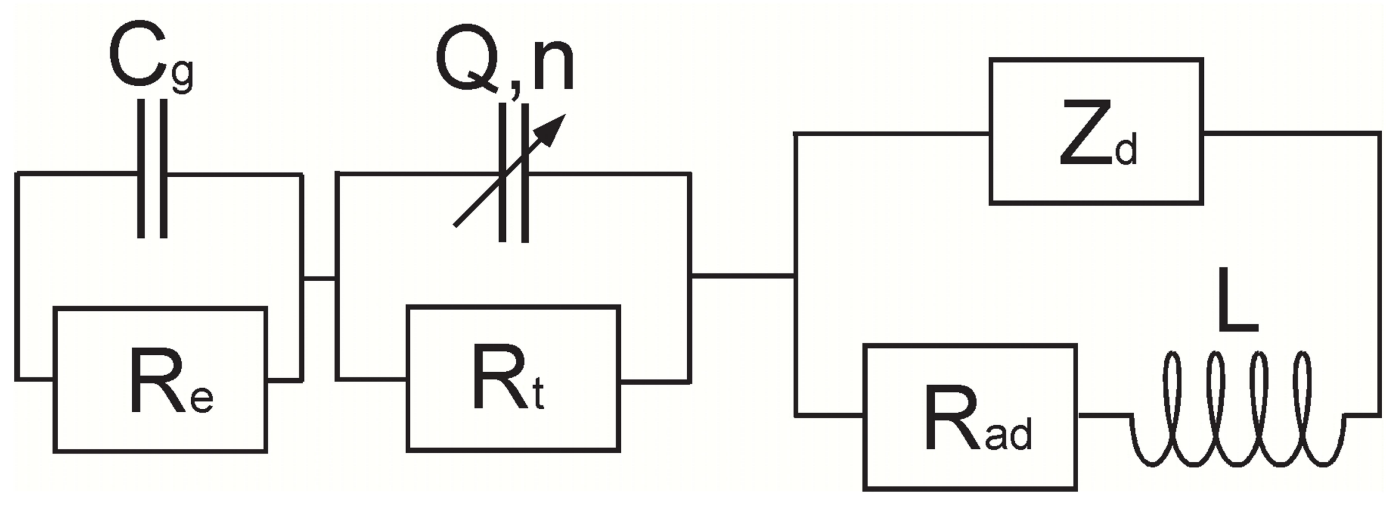

(b)

Figure 7 


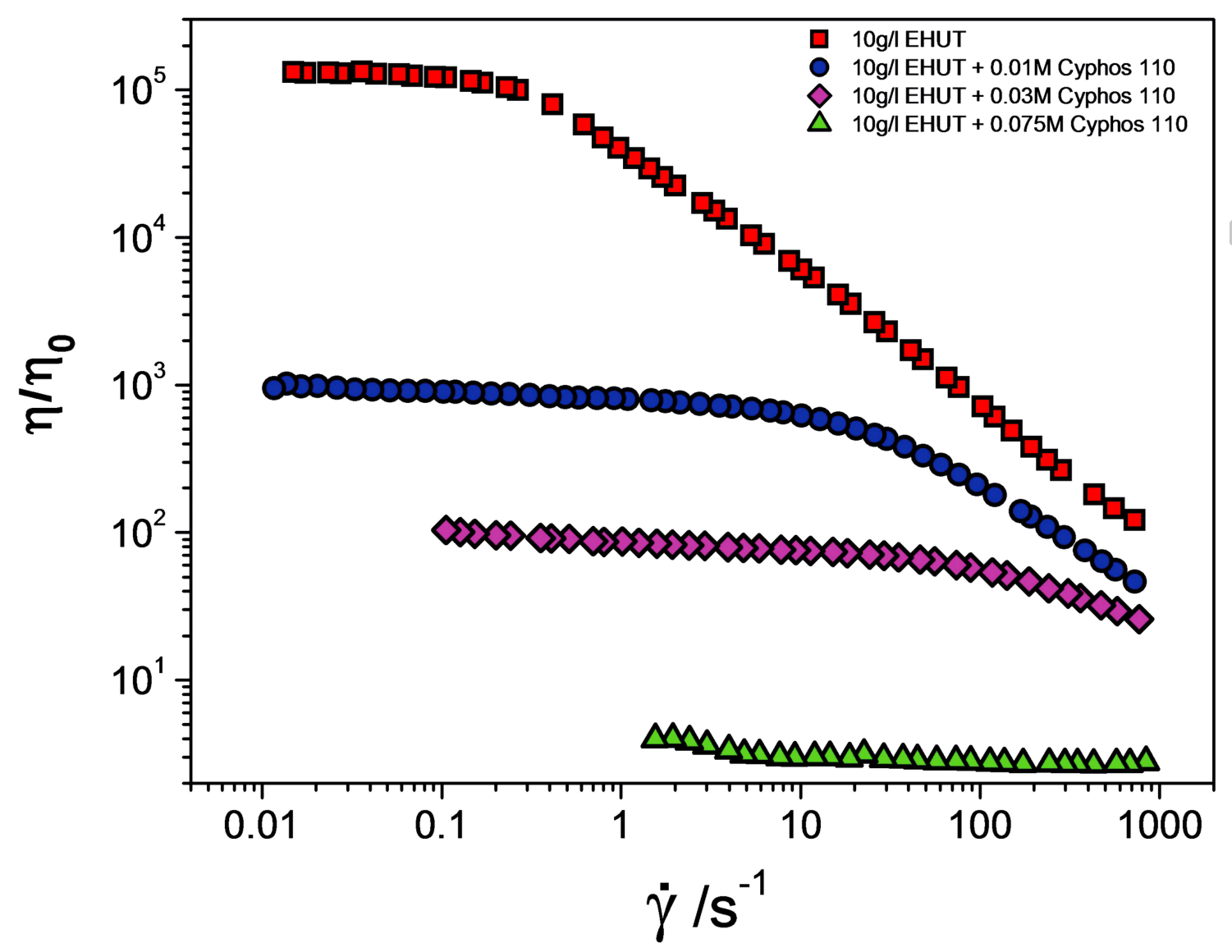

Figure 8 


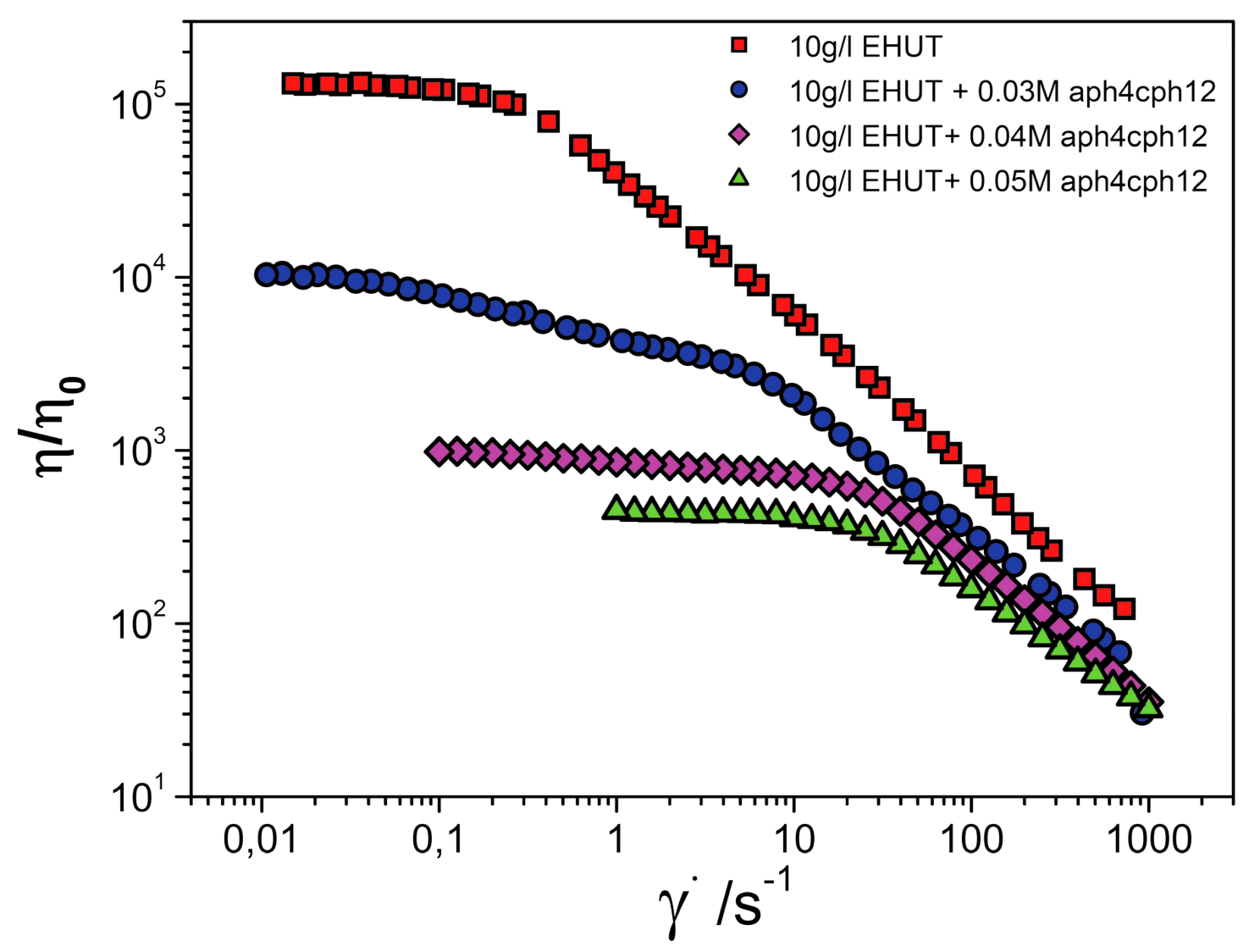

Figure 9 
ACCEPTED MANUSCRIPT

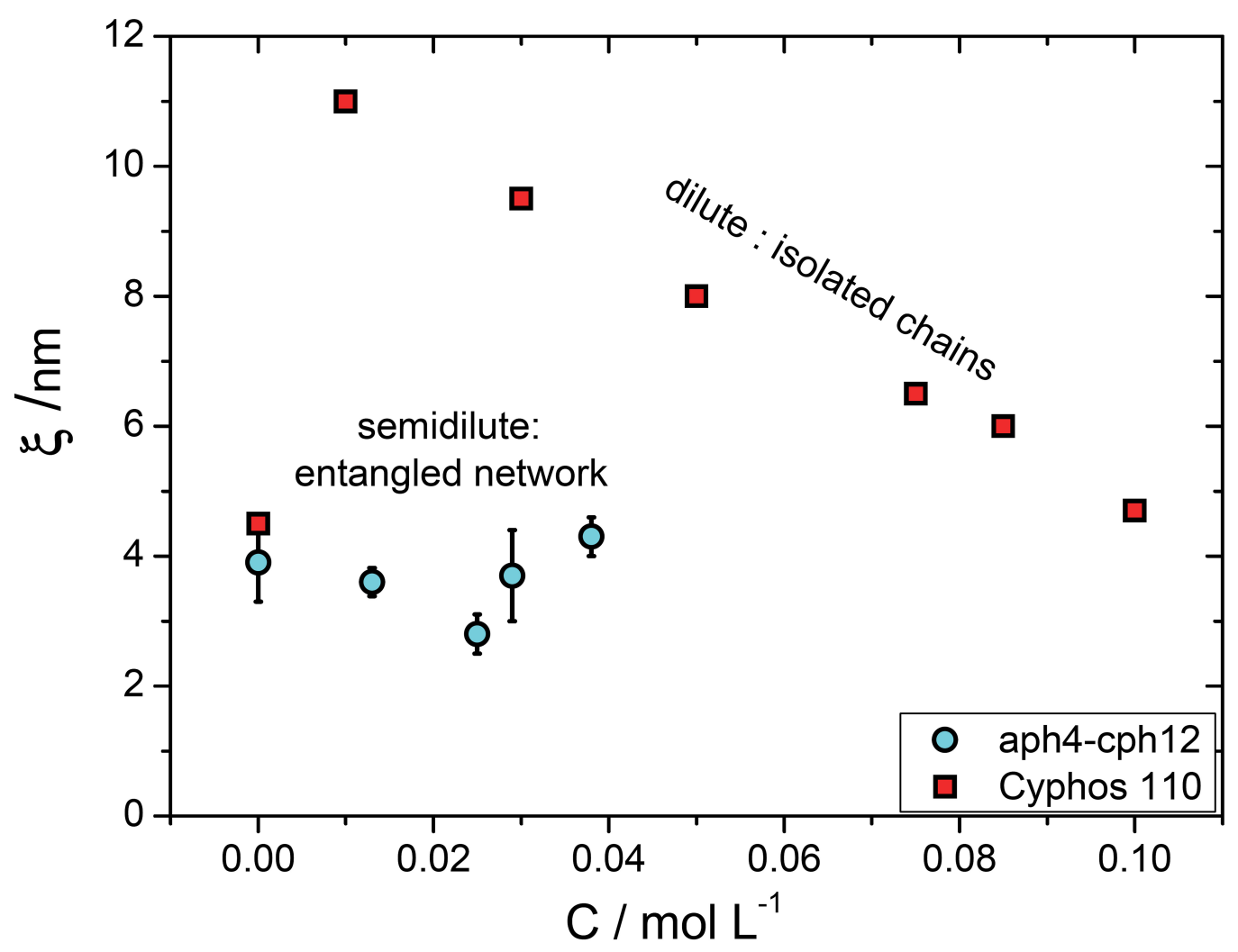

Figure 10 
Table 1 : Parameters values deduced from the data of figures 3 and 4 and calculated from the Levich equation.

\begin{tabular}{|c|c|c|c|c|c|c|c|}
\hline Ionic liquid & $\begin{array}{c}\text { Concentration } \\
\mathrm{mol} \mathrm{L}^{-1}\end{array}$ & $\begin{array}{c}\eta \\
\times 10^{4} \\
\text { a.s) }\end{array}$ & $\begin{array}{l}\mathbf{v} \\
\times 10^{2} \\
\left.: \mathrm{m}^{2} \mathrm{~s}^{-1}\right) \\
\end{array}$ & $\begin{array}{r}\alpha \\
\mu \mathrm{A}\end{array}$ & $\begin{array}{c}\boldsymbol{\beta} \\
\mu \mathrm{A} \mathrm{s}^{1 / 2} \\
\mathrm{ad}^{-1 / 2}\end{array}$ & $\begin{array}{l}\text { D } \\
\times 10^{5} \\
\left(\mathrm{~cm}^{2} \mathrm{~s}^{-1}\right)\end{array}$ & Sc \\
\hline Cyphos 110 & 0.075 & 9.3 & 1.065 & 0.485 & 0.23 & 2.785 & 382 \\
\hline Cyphos 110/EHUT & 0.075 & 16 & 1.83 & 0.299 & $0.198 /$ & 2.55 & 11 \\
\hline Cyphos 110 & 0.085 & 9.93 & 1.135 & 0.320 & 0.255 & 3.30 & 344 \\
\hline Cyphos 110/EHUT & 0.085 & 15 & 1.715 & 0.108 & 0.212 & 2.775 & 618 \\
\hline Cyphos 110 & 0.1 & 9.98 & 1.14 & & & & \\
\hline$[\mathrm{Fc}]=1 \mathrm{mM}$ & $"$ & $"$ & $"$ & 0.298 & 0.246 & 3.11 & 367 \\
\hline$[\mathrm{Fc}]=0.5 \mathrm{mM}$ & $"$ & $"$ & " & 0.245 & 0.151 & 4.25 & 268 \\
\hline$[\mathrm{Fc}]=0.2 \mathrm{mM}$ & $"$ & $"$ & & 0.0542 & 0.068 & 5.04 & 226 \\
\hline Cyphos 110/EHUT & 0.1 & 13 & 1.485 & 0.0124 & 0.227 & 2.97 & 500 \\
\hline aph4-cph12 & 0.03 & 538 & 0.61 & 0.203 & 0.256 & 2.96 & 206 \\
\hline aph4-cph12 & 0.04 & 5.5 & 0.63 & 0.03 & 0.275 & 3.296 & 191 \\
\hline aph4-cph12 & 0.05 & 6.13 & 0.7 & 0.124 & 0.276 & 3.31 & 211 \\
\hline
\end{tabular}


Table 2 : Fitted parameters values of the EIS diagrams analyzed with the electrical equivalent circuits (a) or (b) of figure 7

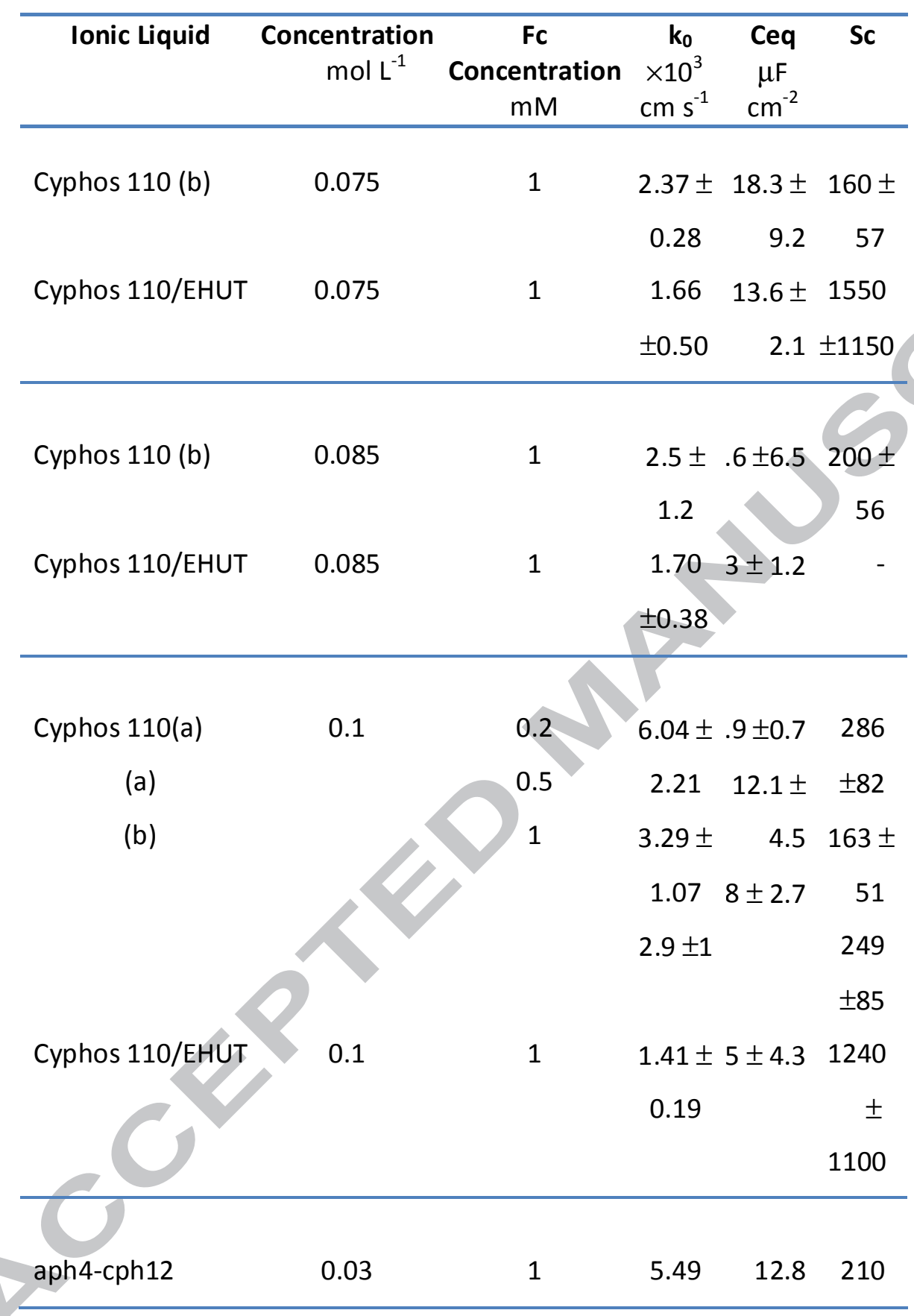

